\title{
Interactive comment on "Predominance of hexamethylated 6-methyl branched glycerol dialkyl glycerol tetraethers in the Mariana Trench: Source and environmental implication" by Wenjie Xiao et al.
}

\section{Anonymous Referee \#2}

Received and published: 30 December 2019

The manuscript by Xiao et al. describes the distribution of branched tetraether lipids in Mariana Trench sediments. Very few studies to date have investigated the organic geochemistry of deep-sea trench sediments and even fewer have studied the distribution of tetraether lipids. The study presented by Xiao et al. thus is a novel contribution to the field. Specifically, the authors show that the distribution of branched tetraethers is unique when compared to previously studied environments.

I have two major criticisms, or suggestions, that the authors should consider in preparing a revised version. 
1) The uniqueness of the study site is both a strength and a weakness of the presented work. It is a strength, as the remote setting may allow distinguishing marine in situ production from a terrestrial origin of brGDGTs that muddles interpretation of shelf sediments. However, it is a weakness because it is unclear how comparable the site is to continental shelf sediments. This is regardless of whether brGDGTs originate from sediments or from the water column, since factors such as nutrients, particle loading, bacterial community composition, oceanographic parameters (oxygenation, salinity, currents etc.) will vary between the shelf and trench sediments and between shelf water column and the pelagic water column above the trench. These points are particularly important since it remains unresolved whether brGDGT production in the ocean originates from the water column or sediments, or both, and which bacterial clades synthesize brGDGTs. The authors should address these caveats in their manuscript. A good place to discuss these issues would be between lines 374-400. This discussion should then be reflected in the revised abstract.

2) I fundamentally disagree with the use of soil calibrations for reconstructing seawater, or porewater, $\mathrm{pH}$ and temperature (lines 360-372). There is no evidence supporting the applicability of these calibrations. Therefore, the brGDGT-based $\mathrm{pH}$ reconstructions cannot be used as evidence for in situ production. Specifically, it is currently unclear if the clades of bacteria producing brGDGTs in soils are similar to those in the ocean, particularly because the perceived adaptation of branched GDGT distributions to environmental parameters has previously been suggested to be a community effect.

I think that the number of figures in the main text could be reduced in order to streamline the manuscript. I suggest moving figures 3-5 to the supplement.

Finally, I recommend the authors carefully examine their manuscript to fix multiple typos and grammar.

Printer-friendly version

In summary, I recommend publication after moderate changes have been made.

Discussion paper

Additional comments: 
All figures: To ensure accessibility, please use color blind-friendly colors, e.g., do not use red and green in the same figure.

Line 8-24: Please correct grammar issues throughout the abstract

Line 16: Please specify that $\mathrm{d} 13 \mathrm{C}$ values are for $\mathrm{OC}$

Line 28-30: Please consider finding more appropriate citations. Sinninghe Damste 2000 and Weijers et al. are neither the first to report on iGDGTs/brGDGTs nor are these the most comprehensive papers.

Line 120-122: Without response factors of GDGTs relative to the C46 standard, concentrations cannot be determined. Please report concentrations as response units or peak areas normalized to OC.

Interactive comment on Biogeosciences Discuss., https://doi.org/10.5194/bg-2019-391, 2019. 